\title{
O ROL DO EQUIPO DE ORIENTACIÓN ESPECÍFICO NOS TRASTORNOS DA CONDUTA
}

\author{
THE ROLE OF THE GUIDANCE SPECIFIC \\ TEAM IN BEHAVIOURAL DISORDERS
}

\author{
José Enrique Abalo Quintela \\ Equipo de Orientación Específico (Pontevedra) \\ Especialista en Trastornos da Conduta \\ abaloquintela@yahoo.es
}

\section{RESUMO}

A conciencia social sobre os problemas de conduta e a convivencia nos centros educativos aumentou significativamente nos últimos anos. Esta circunstancia provocou que se activasen unha serie de vías formativas, marcos normativos e recursos de apoio aos centros para xestionar adecuadamente esta preocupación. Este artigo analiza un deses recursos de apoio, os equipos de orientación específicos, onde existen profesionais dedicados a colaborar, cos departamentos de orientación dos centros e coa comunidade educativa en xeral, na construción de contornos de ensinanza-aprendizaxe adecuados para posibilitar a aprendizaxe, pois convivencia e aprendizaxe condiciónanse mutuamente.

Comezaremos explicando o rol que está previsto que desempeñe este servizo, describindo o encaixe do mesmo no modelo de orientación deseñado para a Comunidade Autónoma de Galicia: funcións, liñas previstas de intervención, así como os protocolos xerais a seguir.

O núcleo principal do artigo expón os principios nos que inciden as intervencións. Destacando a importancia de colaborar coas institucións escolares na creación de culturas inclusivas, actuacións proactivas e metodoloxías colaborativas e cooperativas como vías eficaces para xerar climas escolares onde se favoreza a comunicación, o respecto mutuo, o diálogo e o protagonismo dos distintos actores que interaccionan neses espazos.

Palabras clave: convivencia, trastornos da conduta, habilidades sociais, intelixencia interpersoal.

\section{ABSTRACT}

Social awareness concerning behavioural problems and coexistence in schools has significantly increased in recent years. This circumstance led to the introduction of a series of training channels, regulatory frameworks and resources to support schools in order to adequately manage this concern. This article analyses one of these support resources, the specific guidance/orientation teams, where there are professionals devoted to cooperate with the orientation departments of schools and with the educational communities in general, to build appropriate teaching-learning environments for making learning possible, since coexistence and learning are mutually conditioned. 
We will begin by explaining the role which this service is expected to play, describing its fitting in the orientation model designed for the Autonomous Community of Galicia: Functions, planned lines of intervention, as well as the general protocols to follow.

The focus of this article explains the principles upon which the interventions are based. Emphasising the importance of collaborating with school institutions to create inclusive cultures, proactive actions and collaborative and cooperative methodologies as effective ways to generate environments which encourage communication, mutual respect, dialogue and the leading role of the different agents that interact in these spaces.

Key words: coexistence, behavioural disorders, social skills, interpersonal intelligence.

\section{O EOE NO ESQUEMA DO MODELO ORIENTATIVO}

O Equipo de Orientación Específico (EOE) é un recurso, externo aos centros, o seu ámbito de actuación é de carácter provincial e abrangue ao conxunto de escolas, centros e institutos que imparten as ensinanzas non universitarias. Está composto por especialistas en: discapacidade sensorial, altas capacidades, discapacidade motórica, trastornos da conduta, trastornos xeneralizados do desenvolvemento, orientación vocacional e profesional, traballo social e audición e linguaxe.

A especialidade de conduta ofrece colaboración e asesoramento aos centros educativos e á administración educativa (inspección, xefatura territorial de educación, outros servizos, ...) na elaboración das respostas educativas adecuadas dirixidas ao alumnado con trastornos graves de conduta e á mellora da convivencia nos centros.

\section{Funcións específicas}

Esta estrutura de apoio aos centros ten previsto, de acordo coa normativa, unha serie de funcións que podemos agrupar ao redor das seguintes áreas:

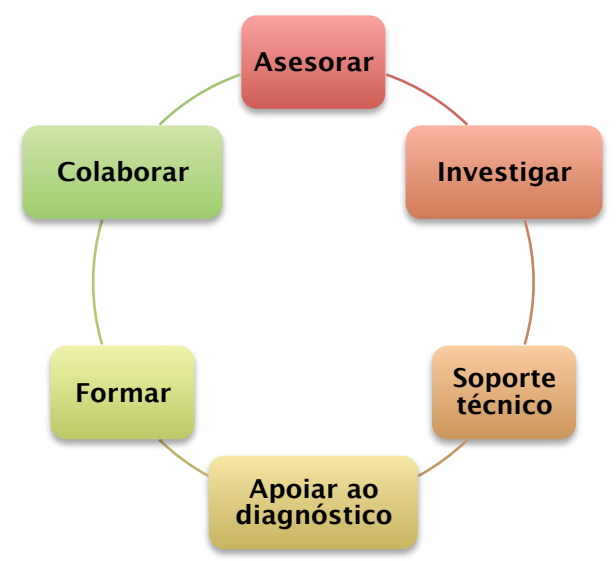

Figura 1: Soporte técnico. Fonte: elaboración propia 
De asesoramento:

- Aos Departamentos de Orientación (DO) na identificación e elaboración dos modelos de resposta aos problemas de convivencia e conduta.

- Intervir e asesorar, cando cumpra, coas familias e con outros axentes do contorno, a efectos de prevención de problemas de conduta.

De investigación:

- Da incidencia dos trastornos de conduta de cada provincia.

- Sobre indicadores de risco que poidan provocar situacións conflitivas nos centros.

- Sobre os tipos e formas de xestión dos conflitos de convivencia nos centros educativos.

De soporte técnico:

- Co obxectivo de elaborar e difundir materiais de apoio aos DO e ás titorías que favorezan unha resposta educativa adecuada aos trastornos de conduta.

- Sobre bibliografía ou/e webgrafía novidosa e relevante.

De apoio ao diagnóstico:

- Participando, se é o caso, nos ditames de escolarización máis axeitados para o alumnado afectado por trastornos de conduta.

- Colaborando na avaliación psicopedagóxica cando se considere necesaria a intervención dun especialista externo ó centro.

De formación:

- Elaborando, en base ás demandas e necesidades percibidas, propostas para integrar nos plans anuais de formación dos/as orientadores/as e profesorado.

- Das familias para que poidan incidir positivamente no proceso educativo dos/as seus/as fillos/as.

De colaboración:

- Colaborando con outros servicios que inciden na comunidade educativa: Xefatura Territorial de Educación, Inspección Educativa, Centros de Formación e Recursos, servizos sociais, unidades de educación familiar dos concellos, servizos de atención ao menor, servizos de saúde mental, etc. 


\section{A INTERVENCIÓN}

\section{a) Liñas de intervención}

A intervención nos centros pode activarse de tres maneiras:

- Para desenvolver o plan anual, elaborado a principios de curso, tanto na parte xeral do EOE como na específica de cada especialidade.

- En resposta a demandas concretas que poden producirse por solicitude do/a xefe/a do departamento de orientación, do/a director/a do centro (xuntando o informe da xefatura do departamento de orientación), co visto e prace da inspección do centro, ou por proposta desta última.

- Por requirimento da Administración Educativa.

A parte, o EOE actúa, seguindo unha vía máis informal, que non require demanda, nin programa previo, e que se concreta na resposta a consultas vía telefónica, páxina web ou correo electrónico, sobre cuestións relacionadas co ámbito da conduta (alumnado con problemáticas condutuais, posibles medidas de escolarización, materiais a utilizar, posibles vías para dar resposta á diversidade, ...).

Para as actuacións que se concretan a través dunha solicitude de intervención, existe un formulario modelo ${ }^{1}$. Está liña sempre terá un carácter complementario e de axuda ás intervencións previas que deben realizar os propios recursos dos centros. Neste caso, priorizaranse as intervención sobre o alumnado:

- Que se considere que as medidas adoptadas polo centro non están reconducindo a situación e necesitan, polo tanto, ser revisadas ou axustadas.

- Que "provoca” condutas que están afectando á integridade física ou psicolóxica del mesmo ou dos que o rodean.

- Que interfire moi negativamente no desenvolvemento normalizado das actividades educativas da aula ou do centro.

Para realizar estás intervencións, o solicitante (Orientador/a dun centro, Director/a do mesmo...) sempre deberá trasladar, ao especialista de conduta do EOE, un informe previo coas medidas adoptadas ata o momento e a valoración da eficacia das mesmas.

\section{b) Protocolo básico de intervención}

Prioritariamente ao deseño dun esquema de actuación, é necesario avaliar a situación con precisión. Polo que todo comeza cunha análise das intervencións previas realizadas polo propio centro. É importante valorar en que medida esas actuacións estiveron planificadas, a partir, nunha avaliación completa da situación, que permita entender as causas e a dimensión da problemática que se presenta. Aínda que en certos casos necesitamos incidir e indagar especificamente nos factores de

1 Que se pode localizar en http://www.edu.xunta.gal/portal/diversidadeorientacion/141/649/651 
risco individuais (retraso escolar, conmorbilidades, nivel de CI, presencia de trastornos no contexto familiar, ...), en xeral, será importante valorar:

- A conduta a nivel topográfico: frecuencia, duración, intensidade e respostas de tipo fisiolóxico, motor ou cognitivo que mostra a persoa.

- A conduta a nivel funcional: acontecementos que acostuman a preceder á emisión desa conduta, variables hereditarias ou factores actuais que poden explicar esas reaccións (inxesta de sustancias tóxicas, cansazo, ...), recursos cos que conta o alumnado para dar resposta nese momento (habilidades sociais, capacidade de xestións das emocións, dominio e capacidade de autocontrol, etc.), respostas específicas e consecuencias que recibe (atención dos compañeiros, evitar facer algo que non quería, etc.).

- Ademais é necesario recoller información sobre o alumnado: nivel cognitivo e competencial, estilo de aprendizaxe e ensinanza, contexto familiar e social no que convive, etc.), é dicir, ter moi presente os factores que predispoñen e poden explicar que se dean eses problemas de conduta, así como aquelas condicións e circunstancias que a precipitan e a manteñen. Estas últimas poden aparecer no contexto persoal, familiar, escolar ou social.

\section{c) Ámbitos de intervención}

A media, nos últimos 17 anos, de demandas atendidas, por esta especialidade foron de 227 anuais, procedentes de centros que imparten tódalas etapas educativas.

\section{Demandas de intervención}

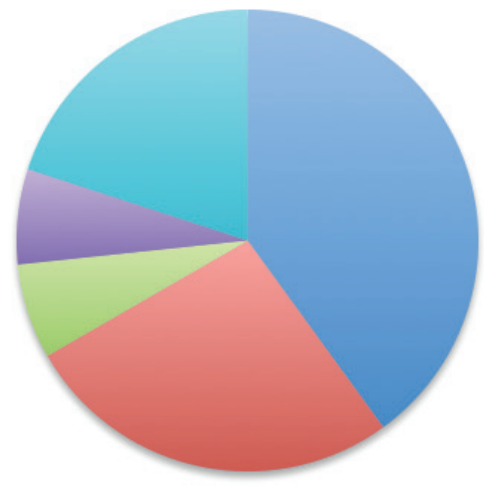

-TDAH

- Condutas disruptivas

Mutismo selectivo

Maltrato entre iguais

outras

Figura 2: Tipo de demandas. Fonte: elaboración propia.

Como podemos observar no gráfico, os tipos de trastornos sobre os que se está solicitando intervención polo EOE serían por este orde: casos de alumnado cun posible perfil TDAH, alumnado 
que mostra condutas disruptivas de diverso grao de complexidade, alumnado con mutismo selectivo, problemas de convivencia escolar relacionados con posibles situación de maltrato entre iguais e outras casos de menor incidencia:

- Alumnado con TICs (Síndrome de Tourette, ...),

- Alumnado con trastornos de personalidae asociados: bipolares, trastorno obsesivocompulsivo, trastorno límite da personalidade.

\section{d) Actuacións}

En xeral, as actuacións implican realizar todas estas accións:

- Análise no centro dos documentos existentes sobre o caso.

- Observación do alumnado en diversos contextos: aula, patio,...

- Entrevistas ou reunións co/a orientador/a, profesorado, familia, etc.

- Concreción e elaboración de pautas de actuación para o contexto familiar.

- Elaboración e remisión ao centro e/ou a inspección do centro do informe sobre pautas de actuación consensuadas ou recomendadas.

Estas actuacións, en ocasións conlevan, outras complementarias.

- Reunións con outros servicios: inspección, servizos sociais e de menores, unidades de saúde-mental infanto xuvenil, etc.

- Elaboración de ditames ou informes de escolarización.

Outras actividades, tamén frecuentes son:

- As reunións con asistentes sociais ou/e educadoras familiares de diversos concellos e con asociacións, á efectos de coordinar as actuacións, en certos casos, nos que a problemática do alumnado está asociada a contextos familiares moi pouco estruturados, neglixentes ou escasamente comprometidos co proceso de reeducación.

- Reunións con representantes dos servicios de menores e responsables de distintas casas de acollida.

- Participación como relator en cursos e realización de charlas sobre temas de conduta en centros.

- Elaboración de instrumentos de recollida de información: cuestionarios, escalas, fichas, etc.

- Difusión de recursos aos centros e aos servizos de orientación en particular.

\section{PRINCIPIOS E VÍAS NAS QUE INCIDIMOS}

Desde está especialidade, a liña de actuación está inspirada nuns principios que poderíamos resumir nos seguintes apartados: 


\section{a) Propostas inclusivas}

Toda a Comunidade debe implicarse. Neste sentido, consideramos fundamental sensibilizar e axudar e dinamizar nas escolas culturas escolares inclusivas. Un estudio desenvolvido polos investigadores da Universidade de Salamanca Ortiz e Lobato (2003), destacan algunhas das dimensións sobre as que incidir para avanzar cara ese tipo de culturas escolares:

- Construír consensos dentro da Comunidade Escolar : debemos de evitar que membros ou sectores da comunidade rexeiten a este tipo de alumnado ou simplemente non colaboren na súa inclusión. É moito máis probable que ese consensos positivos aparezan en escolas onde membros do profesorado ou doutros sectores, que se ubican en posicións de liderazgo, manifesten unha aposta aberta polos valores inclusivos.

- Estes centros, así mesmo funcionan con dinámicas de colaboración e apoio entre o profesorado e os distintos sectores da Comunidade Escolar. Son revisores continuos das súas prácticas educativas e tenden a modificar as estruturas tradicionais de segregación (separación en aulas especiais, control da disciplina utilizando só un enfoque punitivosancionador, ... ). En xeral, son centros con fortes dinámicas de vinculación coa comunidade (familias, profesionais e institucións externas ao centro, ...).

- Apostan por culturas de cambio, que case sempre supoñen asumir riscos e adaptarse ás novas circunstancias.

En base ao anterior, a nosa proposta para dar unha resposta aos problemas de convivencia dos centros ten un carácter procesual é orgánico. Procesual, pois entendemos que as melloras só poden consolidarse se hai un desenvolvemento das capacidade dos membros da propia escola para asumir e xestionar o cambio. Este vai ocorrer de maneira progresiva e vai contribuír ao crecemento da propia escola. Será esta na súa totalidade o obxecto e o axente do cambio, e nese sentido esta proposta ten un carácter orgánico. Coincidindo con Moreno e Torrego (1999), afástase doutras orientacións que podemos denominar de resposta específica, e aínda que para certos casos, moi particulares e de actuación urxente, si utilizamos programas de resposta concreta, consideramos que os esforzos debemos centralos nos cambios das variables organizativas e relacionais que constitúen a cultura dos centros educativos. Polo tanto, procuramos:

- Animar á revisión da situación actual da xestión da convivencia no centro.

- Prestar asesoramento e apoio, a través dos departamentos de orientación, equipos directivos e os equipos docentes, para crear as condicións necesarias que permitan abordar os conflitos de convivencia.

- Asesorar ao profesorado titor, dando respostas ás súas demandas e necesidades.

- Prestar apoio específicos para desenvolver as liñas de traballo acordadas no plan de convivencia que elabore a comisión de convivencia do centro.

- Abordar e analizar cos afectados as resistencias e dúbidas que puideran manifestarse. 


\section{b) Actuacións proactivas}

A idea de proactividade, oponse a de reactividade. Actuar de forma proactiva supón anticiparse e implica centrarse no pasado e nos feitos, pero só como punto de partida para autorevisar o estado da convivencia, tratando de ser o máis realista e concreto posible. Trátase de construír unha visión compartida e ordenada, que permita analizar as causas dos problemas e as debilidades e fortalezas do Centro. Tampouco supón a eliminación total do modelo sancionador, xa que este usarase, segundo os protocolos, previstos nas normas de organización, funcionamento e convivencia aprobadas en cada centro, para aquelas condutas que persistan, de tipo leve ou grave contrarias á convivencia, incluso despois de realizar a intervención educativa de tipo proactivo.

O enfoque proactivo busca mellorar a convivencia e ensinar a convivir incidindo nos aspectos relacionais. Nesta proposta priorizase a reflexión, o diálogo entre as partes, a construción de acordos, os valores de colaboración e compromiso. En definitiva, buscamos poñer aos protagonistas da convivencia na médula dos procesos de mellora e darlles a oportunidade de elixir o que queren facer.

Algunhas das propostas, nas que máis colaboramos, para avanzar cara ao modelo anterior son as seguintes:

- Colaborar para que na elaboración do Plan de Convivencia dos centros se inclúan medidas orientadas a ensinar a convivir, activando propostas de carácter educativo. Isto supón integrar distintas competencias nos programas escolares relacionadas coas capacidades de: ensinar a pensar sobre as nosas condutas, aprender a xestionar ben as emocións que xeran conflitos, interiorizar valores positivos, desenvolver habilidades socio-comunicativas, .... .

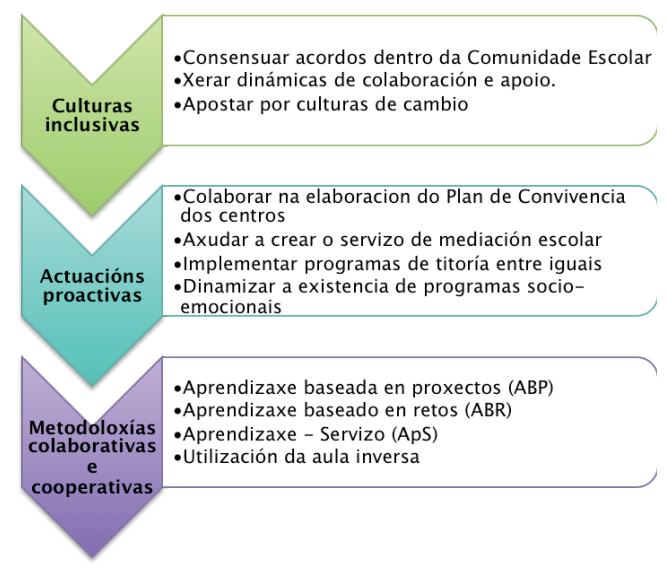

Figura 3: Principios e vías de intervención. Fonte: elaboración propia.

- Dinamizar a implementación de medidas como:

- A creación do servizo de mediación escolar: Por mediación entendemos un proceso no que as partes en conflito son asistidas por un terceiro, o mediador, alleo e imparcial ao conflito, aceptado polas partes, e que a través de técnicas adecuadas axuda a que 
as partes en litixio cheguen a un acordo por medio do diálogo e da negociación. $\mathrm{O}$ mediador ou mediadora deberá axudar a limpar a relación emocional negativa que se da entre as partes, e contribuír a regular o proceso de comunicación e o establecemento de acordos propios. A mediación é un método alternativo, creativo, non adversial e estruturado.

- Método alternativo, pois é unha vía distinta a vía instrutiva ou ao procedemento conciliador previstas no Decreto 8/2015. A solución non é imposta por terceiras persoas, senón que serán as partes en litixio as que deben creala.

- Método creativo porque promove a busca de solucións novas, "creadas" polas partes, en ocasións máis alá do previsto reglamentariamente.

- É unha vía non adversial, porque evita a tradicional concepción "gañar-perder" nos conflitos, e aspira a atopar unha solución que responda ao esquema "gañargañar", unha solución que satisfaga a ámbalas partes.

- Finalmente é un método estruturado, pois supón ter previstos uns protocolos e repetar unhas fases para que sexa eficaz (premediación, presentación das normas, relatar o conflito, situar o conflito, buscar solucións, asinar un acordo).

$O$ obxectivo último dun programa de mediación escolar é a solución pacífica e dialogada dos conflitos entre os membros da comunidade escolar. Conflitos que non puideron ser solucionados polos protagonistas, nin por medio da mediación informal. Pero o servizo de mediación debe contribuír a alcanzar outros obxectivos máis específicos en coherencia con esa misión educativa que ten e que serían:

- Reconstruír relacións deterioradas entre membros da Comunidade Escolar.

- Contribuír a mellorar a capacidade de relación interpersoal.

- Mellorar a competencia social e cidadá

- Aumentar a capacidade de resolución de conflitos.

- Desenvolver a capacidade de autorregulación, a través da busca de solucións creativas e negociadas.

- Implicar aos membros da comunidade educativa.

- Axudar ao alumnado a desenvolver a confianza nas súas habilidades.

- Pensar creativamente sobre os problemas e comezar a solucionar conflitos.

- Os programas de titoría entre iguais (TEI). Sería outra medida preventiva contra a violencia e o acoso escolar, que implica a toda a comunidade educativa. Con este recurso intentamos empoderar ao alumnado como suxeito protagonista da convivencia e a prevención da violencia.

- Os programas e prácticas orientadas a abordar os aspectos emocionais e de formas de pensamento que están detrás das condutas observables. Serían un campo moi amplo de propostas que podemos clasificar en varios grupos:

- As dirixidas a reorganizar procedementos cognitivos. Así pautar programas de autoinstrucións, de resolución de conflitos, de análise de consecuencias, de problema-solución ou de reestruturación cognitiva serían algúns dos que insistimos nos procesos de asesoramento ao equipo orientador e ás titorías dos centros. 
- As orientadas a mellorar o ámbito socio-emocional. Neste caso estarían as indicacións dirixidas a repensar a organización da aula (distribución grupal, organización do espazo e distribución do horario escolar), á mellora da cohesión grupal (propostas de traballo cooperativo, realización de actividades de coñecemento e vinculación emocional entre o grupo), os programas de desenvolvemento de habilidades sociais ou o impulso das dinámicas de participación do alumnado e das familias na elaboración das normas e na xestión da convivencia. Brackett, Mayer e Warner (2004) contrastaron que o desenvolvemento da intelixencia emocional correlaciona positivamente co benestar persoal e diminúe os comportamentos disruptivos. Si é importante destacar que o traballo neste ámbito require un adestramento continuado, xa que senón os beneficios duran pouco tempo (Durlak et al. 2011).

- As orientadas a construír un currículo integral e inclusivo. Aquí estaría o asesoramento dirixido a integrar na aula o traballo e avaliación de tódalas intelixencias ás que se refire H. Gardner, a incorporación á aula de prácticas extraídas do ámbito da psicoloxía positiva (actividades de atención plena, o traballo das fortalezas que propón Seligman, ou as actividades de Mindfulness, ...). Sobre isto último, é necesario destacar a influenza que sobre a mellora do clima de aula ten a práctica da relaxación-mindfulness co alumnado. Numerosas estudios como os de Zoogman, Goldberg, Hoyt e Miller (2014); ou de López-González e Oriol (2016), confirman esa conexión entre práctica de relaxación-mindfulness, mellor clima de aula e indirectamente mellor rendemento académico.

- Non podemos esquecernos, por outra banda, dos cambios que en moitos casos é necesario introducir para traballar realmente na aula e logo avaliar todas as competencias claves. O dito supón asumir que debemos realizar modificacións importantes nas programacións didácticas de aula (modificando obxectivos, contidos ou estándares de avaliación), tanto a nivel grupal como individual.

- Finalmente, non esquecemos o rol que como técnicos asumimos, aos efectos de valorar a necesidade de recursos humanos ou materiais, necesarios para atender con dignidade certas situacións e problemáticas, que en relación á convivencia escolar se dan nos centros educativos.

\section{c) Dinamización de metodoloxías colaborativas e cooperativas}

Potenciar cambios metodolóxicos na aula pode facilitar que se atenda mellor á diversidade e que esa aprendizaxe sexa solidaria. Esa modificación da praxe educativa nas aulas sería unha maneira máis de mellorar a convivencia. Pensamos que é necesario impulsar propostas que fomenten a aprendizaxe colaborativa e cooperativa, que aínda que presenta algunhas diferencias, coinciden en ser dinámicas de traballo que aportan ao alumnado beneficios moi desexables para aprender a convivir. Entre outras:

- Promoven valores como a responsabilidade individual e compartida, a empatía, a solidariedade e a cooperación.

- Favorecen o desenvolvemento de habilidades interpersoais e sociais: a escoita activa, a participación, a asunción de retos en común ou a capacidade de coordinación e chegar a acordos. 
- Permiten que o alumnado máis introvertido e illado atópese nun contorno propicio para a interacción, o que pode axudarlle a disminuír os sentimentos de illamente e acharse máis protexido polo grupo.

Algunhas das formas de introducir prácticas cooperativas e colaborativas serían a través de métodos como:

- A aprendizaxe baseada en proxectos $(A B P)$ e a aprendizaxe baseada en retos (ABR) .

- As propostas de Aprendizaxe-Servizo $(A p S)$ como unha forma de abrir os centros ao contorno e implicar á comunidade. As $A p S$ fortalecen o capital social das comunidades, eleva o compromiso e o autocontrol. Ofrecen oportunidades para aprender valores fundamentais para convivir (compromiso, solidariedade, esforzo, planificación, autocontrol e competencias interpersoais) desde a experiencia e a construción de hábitos. Son, por tanto, unha vía para traballar a convivencia en positivo. Se queremos que os/as xoves aprendan a ser bos/as cidadáns, temos que ofrecerlle no tempo da escola oportunidades para practicar e entendemos que as ApS son unha oportunidade excelente.

- Utilización progresiva da aula inversa. Ao incentivar dinámicas de participación e cooperación pode mellorarse o clima da aula e como consecuencia a convivencia. Este modelo educativo, facilita as posibilidades de atención á diversidade, aumenta a interacción, a personalización e o contacto entre profesorado e alumnado, polo que poden mellorarse as relacións persoais.

\section{ALGUNHAS CONCLUSIÓNS}

Apostar por unha abordaxe proactiva, que serían todas aquelas actuacións e aprendizaxes que podemos realizar nas aulas para prever a aparición de condutas problemáticas. O enfoque que propoñemos considera que non podemos percibir ao alumno como un ser illado e interpretar as súas condutas como algo só dependente del. Estas non poden entenderse independentemente do contexto no que se atopa, polo que debemos realizar unha coidadosa análise dese contexto para determinar as actuacións e as aprendizaxes necesarias para aprender a convivir. Este enfoque retoma un suposto básico da psicoloxía ecolóxica segundo o cal, cando un contexto responde ás necesidades do alumnado, os seus comportamentos non soen ser problemáticos.

Orientar as intervencións en optimizar o ambiente de ensinanza-aprendizaxe na vía de fomentar unha convivencia positiva, polo que debemos axudar a : mellorar a xestión da aula, enriquecer o currículo (ensinar intelixencia interpersoal, traballar tódalas competencias...), introducir prácticas colaborativas e cooperativas (ABR, actividades servizo... ), dar protagonismo e participación á comunidade educativa (creando o servizo de mediación escolar, activando programas como o de titorías entre iguais, modelando procesos de resolución de conflitos na aula...).

É necesario que a educación emocional e a ensinanza de habilidades sociais sexan incluídas no currículo ordinario, para que teñan unha presencia continuada na aula, única forma de garantir a súa eficacia.

Os datos dos anos de traballo desde o EOE, no ámbito dos problemas da conduta, demóstranos a relación directa entre contexto familiar e conduta. Así mesmo, investigacións como a realizada por 
Solís-Cámara, Medina e Díaz (2014) e outros moitos estudios sobre crianza demostran a influencia do tipo de interacción recíproca pais-fillos e nos leva a distinguir entre factores de risco e protectores dos problemas de conduta. Será pois fundamental, realizar plans desde os centros para informar e formar ás familias sobre este aspecto, pois a intervención correcta das familias desde idade temperá é un factor protector e decisivo para prever os problemas de conduta.

\section{intervencións individualizadas}

Actuación con alumnado con características biolóxicas específicas

Intervencións con alumnado que presenta condutas disruptivas de "tono menor".

\section{Intervencións globais e proactivas con toda a Comunidade Educativa}

Figura 4: ámbitos de intervención. Fonte: elaboración propia.

En definitiva, as actuacións neste ámbito, poderían resumirse nestes niveis:

- Intervencións globais e proactivas dirixidas a todo o alumnado, centradas en crear relacións sociais positivas nos centros e contornos que apoien e ensinen habilidades de relación.

- Actuacións específicas adaptadas a determinados segmentos da poboación escolar, que presenta conductas disruptivas de "ton menor", co fin de prever factores de risco.

- Intervencións con alumnado que mostra problemáticas concretas derivadas de características biolóxicas ou contextuais e que presentan situacións conflitivas frecuentes asociadas a factores de risco moi consolidados.

- Finalmente, intervención inmediata e individual co alumnado que presenta condutas moi conflitivas, aos efectos de minimizar as consecuencias graves que poidan provocar na comunidade escolar. 


\section{REFERENCIAS}

Brackett, M. A., Mayer, J. D. e Warner, R. M. (2004). Emotional intelligence and the prediction of behavior. Personality and Individual Differences, 36, 1387-1402. DOI: https://doi.org/10.1016/ S0191-8869(03)00236-8

Decreto 8/2015, do 8 de xaneiro, polo que se desenvolve a Lei 4/2011, do 30 de xuño, de convivencia e participación da comunidade educativa en materia de convivencia escolar. Diario Oficial de Galicia (27/01/2015), 3885-3935.

Durlak, J. A., Weissberg, R. P., Dymnicki, A. B., Taylor, R. D. e Chellinger, K. B. (2011). The impact of enhancing students' social and emotional learning: A meta-analysis of school-based universal interventions. Child Development, 82, 405-432. DOI: https://doi.org/10.1111/j.1467$\underline{8624.2010 .01564 . \mathrm{X}}$

López González, L. e Oriol, X. (2016). La relación entre educación emocional, clima de aula y rendimiento académico en estudiantes de secundaria y bachillerato. Cultura y educación, 28(1), 130-156. DOI: https://doi.org/10.1080/11356405.2015.1120448

Moreno, J. M. e Torrego, J. C. (1999). Resolución de conflictos de convivencia en centros escolares. Madrid: UNED.

Ortiz, M. e Lobato, X. (2003). Escola inclusiva e cultura escolar: algunhas evidencias empíricas. Bordón, 55(1), 27-39.

Solís-Cámara, P., Medina, Y. e Díaz, M. (2014). Relaciones entre la crianza y factores protectores o de riesgo, antes y después de una intervención para padres. Summa Psicológica, 11(1), 75-87.

Zoogman, S., Goldberg, S. B., Hoyt, W. T. e Miller, L. (2014). Mindfulness interventions with youth: A metaanalysis. Mindfulness, 6(2), 290-302. DOI: https://doi.org/10.1007/s12671$\underline{013-0260-4}$ 